\title{
COEXISTENCE OF PRIVATE FIRMS AND OPEN SOURCE FIRMS UNDER SPILLOVERS AND CONSUMER BIAS
}

Murat YILMAZ1
Received Date (Başvuru Tarihi): 06/10/2017

Accepted Date (Kabul Tarihi): 11/12/2017

Published Date (Yayın Tarihi): 20/12/2017

\begin{abstract}
Open source technologies have been an important divergence from the private production, and some markets have accommodated both open source firms and private firms. We explore the conditions under which such a coexistence of both type of firms can be seen. Through a simple and tractable game theoretical model, with spillovers on the open source production and positive consumer bias for the privately produced good, we analyze the conditions for which, in the equilibrium, a private firm and an open source firm share the market. We find that for large enough consumer bias, the two types cannot coexist, however when the consumer bias is relatively low and the spillover effect is not too strong, then we get a coexistence result.
\end{abstract}

Keywords: Open Source Production, Research And Development, Spillover Effect, Consumer Bias, Dynamic Games

JEL Codes: L17, D21, C72, O32

\section{ÖZEL VE AÇIK KAYNAK FIRMALARIN YAYILMA ETKISİ VE TÜKETICI ÖNYARGISI ALTINDA BIR ARADA BULUNMASI}

ÖZ

Açık kaynak teknolojileri özel üretim teknolojilerinden önemli bir sapma olarak görülmekteler. Bazı piyasalarda hem özel üretim yapan firmaların hem de açık kaynak firmaların aynı anda var olduğunu görmkteyiz. Bu çalışmada böyle bir ortak var olmanın hangi şartlarda gerçekleşebileceğini inceliyoruz. Açık kaynak teknolojisinin üretiminde yayllma etkisi barındıran ve tüketicilerin de özel firma tarafindan üretilen ürüne pozitif önyargı besledikleri sade ve çözülebilir bir oyun teorisi modeli kullanıyoruz. Han gi şartlar altında, dengede, özel firmanın ve açık kaynak firmasının piyasa talebini paylaşabileceklerini analiz ediyoruz. Yüksek pozitif tüketici önyargısı varken her iki firmanın piyasada aynı anda var olamayacağını, ancak pozitifönyargı etkisi görece düşük ve yayılma etkisinin çok güçlü olmadı̆̆ı durumlarda ise bu iki firmanın aynı anda piyasada var olabileceğini gösteriyoruz.

Anahtar Kelimeler: Açık Kaynak Üretimi, Araştırma Ve Geliştirme, Yayılma Etkisi, Tüketici Önyargısl, Dinamik Oyunlar

\footnotetext{
${ }^{1}$ Assistant Professor, Boğaziçi University, muraty@boun.edu.tr $\quad \underline{\text { http://orcid.org/0000-0001-9227-9966 }}$
} 


\section{INTRODUCTION}

Open software development has been a major deviation from the private investment model of innovation. The developers and the innovators of an open source technology freely share the proprietary software that they have developed. For example, Linux, a computer operating system, is evolving with many independent developers revealing the code to develop and refine it. Its source code is Itextit\{open\} in the sense that anyone has free access to it. Among the top two most popular web servers, one has been Microsoft and the other Apache. Since April 1996 until June 2014, Apache, has been dominating the web server market. However, between June 2014 and June 2016, these two web servers were head to head, for almost two years. Since July 2016 Microsoft has picked up and managed to get more than half of the market share by July 2017, Apache still being the second largest. ${ }^{2}$

The success of Apache and other open source developments, and this recent close competition between an open source firm and a private firm rise a number of questions. One question is how and under which conditions do these firms, one private and one open source, coexist in a market? Our aim is to shed some light on this question, through a simple and tractable game theoretical model.

We will focus on a market model where two firms are operating, and each will have the choice of being a private firm or an open source firm. Once they choose what type of firm they want to be, they will be investing in their quality levels simultaneously, through costly R\&D. The open source firm will have a cost advantage when conducting $R \& D$, thanks to its large group of open source innovators, that is, there is some spillover affect to some degree on the open source production. However, the private firm will also have an advantage, which is in form of the demand side's preferences. The buyers will be assumed to be positively biased towards a private firm, since it is usually known, for instance, that the customer service of a privately produced good tend to be better than an open source product, also, that privately produced goods are perceived to be less risky in the sense that if it breaks the company may replace it more easily than an open source firm. This consumer bias will affect the market share of each firm, given their quality levels. We will incorporate these two advantages of each side, and work out the equilibrium of the game.

\footnotetext{
${ }^{2}$ See https://news.netcraft.com/archives/category/web-server-survey/
} 
We will show that when the positive bias towards the privately produced good is large enough, the equilibrium cannot entail two different types of firms, there will be either two private firms or two open source firms. However, if this bias is not as large enough, then depending on the cost advantage of the open source firm, coexistence of both types in the equilibrium is possible. More precisely, if the cost advantage is not strong enough, then in the unique equilibrium outcome, there will be one private firm and one open source firm. This result is parallel with the observation that Microsoft and Apache have coexisted in the web server market for a long period of time and with very close market shares, since June 2014 up until June 2016.

\subsection{Literature Review}

The literature regarding the open source economics has been growing since early 2000s. Lerner and Tirole $(2002,2005)$ provide a general discussion of the economics of open source development and lay out a broad literature review. They point out that the open source developers receive a direct effect in the form of improved open source, since they directly benefit from it, and an indirect effect through signaling their abilities and through reputational gains. They show that the literature mostly considers individual motives, incentives to adopt open source softwares and the effect of competition within an open source environment. ${ }^{3}$ Athey and Ellison (2014) use a dynamic model where the open source user/programmers are motivated by reciprocal altruism. The evolution of the open source depends on the quality and the altruistic developers. Bitzer, Schrettl and Schröder (2007) provide a dynamic model of private provision of a public good and focus on the intrinsic motivation of the programmers to explain the open source development.

Since there is a public good nature in open source innovations, a good amount of the literature focuses on the open source development as a public good and uses a static approach. For instance, Johnson (2002) takes a public good approach and uses a static model of private provision of a public good to present welfare results and comparative statics. Modica (2012) considers a two-stage (otherwise static) oligopoly game using a circular city approach and models the open source development from a public good perspective. ${ }^{4}$ Atal and Shankar (2014) model the open source development through quality competition in a public good setting. A closely related study is Llanes and Elejalde (2013), where they explore the open source

\footnotetext{
${ }^{3}$ See Lerner, Pathak and Tirole (2006) for an empirical study on the dynamics of contributions to open source software projects.

4 When there is innovation the new unit cost is $c_{n e w}=(1-b) c_{0}$, where $b \in(0,1)$ and $c_{0}$ being the initial unit cost. Also see Aghion, Harris, Howitt and Vickers (2001), where a firm's unit cost depends on its technology level and when a firm advances its technology level by one step, it sunit cost decreases by some factor.
} 
participation decision of $\mathrm{n}$ firms, their R\&D investment decisions and the prices they pick, using a two-stage game. They characterize the conditions for open-source firms and proprietary firms to coexist.

Economides and Katsamakas (2006) study different industry structures, vertically integrated proprietary, vertically disintegrated proprietary, and open source platform with proprietary applications, and show that the profits are highest for the vertically integrated proprietary industry structure. Jaisingh, See-To and Tam (2014) study the effect of existence of an open source software on the behavior of a firm developing a closed source software, on its resource investment and its pricing decision, through a duopolistic framework, where the investment increases the quality and then the price the firm picks determines its demand. Li and Ji (2010) consider a duopoly model where the firms can reduce cost through $R \& D$ and compare the welfare effects of price and quantity competition in the presence of technology licensing. They show that Cournot competition results in lower prices, lower industry profit, higher consumer surplus and higher social welfare than Bertrand competition. Mustonen (2005) considers the decision problem of a firm which either chooses to support an existing open source program or not. When the firm supports the open source program, the programs become compatible and there are network effects. ${ }^{5}$ Casadesus-Masanell and Llanes (2011) use a mixed duopoly model where a profit maximizing firm competes with an open source firm, which aims to maximize the value of its open software. ${ }^{6}$

Among the dynamic models studied, Yildirım (2006) considers the free-rider problem when the incentive to induce others to contribute by contributing more is present. ${ }^{7}$ Caulkins et al. (2013) study the question of how long does a firm keep its software proprietary and when does it release it to be open source, over a continuous time dynamic model where firms invest in quality and pick own price for its software and complementary product. Kurt and Zaccour (2011) study a similar problem through a 3 stage duopoly game, where they characterize the conditions under which it is optimal for a firm to open its code. Casadesus-Masanell and Ghemawat (2006), in a dynamic mixed duopoly model, study the competition between an open source firm and a proprietary firm, when there is demand-side learning. They show that the proprietary firm stays in the market even if there is an unbounded learning in the open source

\footnotetext{
${ }^{5}$ He characterizes the conditions under which supporting is optimal and also shows that a larger open source programmers' community does not necessarily increase the welfare.

${ }^{6}$ Assuming the product packages are composed of a base module, an extension module and a complementary service, they consider pure and mixed business models. Under compatibility and incompatibility, they solve for the set of optimal business models.

${ }^{7}$ For more on dynamic voluntary contribution games see, for instance, Admati an d Perry (1991) and Marx and Matthews (2000).
} 
side. Suh and Ylmaz (2017) analyze the effects of General Public Licence (GPL) on the firms decisions whether to use the open source technology or not and on their incentives for innovation. Their model include a ladder type technology and firms invest in reducing the cost of production. ${ }^{8}$

Among other R\&D related studies, Reisinger, Ressner, Schmidtke and Thomes (2014) con- sider a model where firms produce a private good and invest in the quality of a public good, like an open source project. ${ }^{9}$ Erkal and Minehart (2014) study the dynamic games of $\mathrm{R} \& \mathrm{D}$, where they explore the effect of knowledge sharing and incentives to license the intermediate steps as they approach the product market competition. ${ }^{10}$

We provide a simpler model that captures, through model parameters, the effect of open source community on the cost of any quality level, as well as the positive bias towards a private firm's product when the other option is the open source product. In these aspects, our approach differs from these studies in the literature.

The paper is organized as follows. Section 2 depicts the theoretical model. In Section 3, we solve the strategic game we describe and characterize the equilibrium. We summarize our findings at the end of Section 3, in Proposition 1. Section 4 concludes.

\section{MODEL}

In order to study, the interaction between two firms, each facing the option to be a private firm or an open source firm, we provide a simple game theoretic model where there are two firms, firm 1 and firm 2, producing the same product, but with potentially different quality levels. The strategic game we consider is dynamic and has two stages. In the first stage of the game, each firm decides whether to be a private type firm or an open source type firm, $\boldsymbol{P r}$ or $\boldsymbol{O p}$. In the second stage, each firm picks a quality level, $q_{i}$, which is achieved by through investing in costly $\mathrm{R} \& \mathrm{D}$. The cost of achieving a quality level, $q_{i}$ through $\mathrm{R} \& \mathrm{D}$ is given by $c_{k}\left(q_{i}\right)$, where $k=\{p r, o p\}$. However, this cost function is different for a private firm and an open source firm: For a private firm, the cost of $q_{i}$ is given by $c_{p r}\left(q_{i}\right)=q_{i}{ }^{2} / 2$ whereas, for an open source firm, it is given by $c_{o p}\left(q_{i}\right)=\alpha q_{i}^{2} / 2$, where $\alpha \in[0,1)$. Here, $\alpha$ measures the degree of spillover effect of the open source community, the firm belongs to. For an open source firm, the lower the $\alpha$ parameter is the lower the cost of attaining a given quality level, that is, when $\alpha$

\footnotetext{
${ }^{8}$ For more on duopolistic competition related studies, see also Haruvy, Sethi and Zhou (2008), Bitzer (2004), Hasnas, Lambertin i and Palestini (2014) and Akbulut and Yilmaz (2015).

9 They find that, under super additive investment cost function, if there is an additional firm or there is a government contribution to the public good, then all firms increase their contributions, that is, they get a crowd-in effect.

10 See also Grossman and Shapiro (1987), Aoki (1991) and Fershtman and Malkovich (2010).
} 
is smaller, the open source community is more effective in cost reduction, that is, larger spillover effect. If $\alpha=1$ then there is no spillover, and being an open source firm does not have any advantage. But for any $\alpha<1$, the open source community provides the open source firm with some cost advantage, due to spillovers.

At the end of the second stage, given the quality levels, the two firms share the market demand according to their quality levels through the following mechanism: If both firms are the same type, their market shares are proportional to their quality levels: firm $i$ 's share is given by $s_{i}=q_{i} /\left(q_{i}+q_{j}\right)$, where $j$ is the other firm. If the firms are different types, then the market shares are determined according to the following: if private firm's quality is given by $q_{p r}$ and the open source firm's quality is given by $q_{o p}$, then the market shares are

$$
s_{p r}=\frac{q_{p r}+\beta q_{o p}}{q_{p r}+q_{o p}} \text { and } s_{o p}=\frac{(1-\beta) q_{o p}}{q_{p r}+q_{o p}}
$$

where $\beta \in(0,1]$ captures the fact that the demand side of the market is positively biased towards the private firm, and the share of the open source firm is reduced by the fraction of $\beta$ if the other firm is private, given each firm's quality level. Higher $\beta$, higher the positive bias towards a private firm. If $\beta=0$, then the demand side is not biased at all, and then if the firms are of different types, the shares are determined proportional to their quality levels. If $\beta=1$, then the demand side is fully biased and the private firm gets the entire market demand, even if its quality level is not as high as the open source firm's quality level. ${ }^{11}$

The profit of firm $\mathrm{i}$ is given by $\pi_{i}=P s_{i}\left(q_{i}, q_{j}\right)-c\left(q_{i}\right)$, where the total demand is normalized to 1 , thus, $1 \cdot s_{i}$ reflects the total quantity, firm $i$ sells. Also, we abstract from the pricing issues, by assuming the ongoing market price is given by $P>0$, which is large enough that any firm finds it optimal to invest in positive quality levels through some R\&D investment. We also assume that the willingness to pay of buyers is also large enough such that at this price each buyer is willing to buy.

In our model, we have two critical parameters, $\alpha$ and $\beta$, the former measuring the spillovers, that is, the effectiveness of the open source community in our context, and the latter measuring the bias of the buyers towards the private firm's product. In the next section we will solve this dynamic game using subgame perfect Nash equilibrium, starting from the last stage. And we will find the equilibrium quality choices as well as the type choices of each firm, as a function of the model parameters.

\footnotetext{
11 Also note that, in case the firms are of different types, the shares we define add up to 1 , as it should be: $s_{p r}+s_{o p}=\frac{q_{p r}+\beta q_{o p}}{q_{p r}+q_{o p}}+\frac{(1-\beta) q_{o p}}{q_{p r}+q_{o p}}=$ $\frac{q_{p r}+\beta q_{o p}+q_{o p}-\beta q_{o p}}{q_{p r}+q_{o p}}=\frac{q_{p r}+q_{o p}}{q_{p r}+q_{o p}}=1$.
} 


\section{EQUILIBRIUM}

To solve the equilibrium of the strategic game described above, we use subgame perfect Nash equilibrium, thus we first solve the Nash equilibrium of each subgame starting from the second stage.

In the second stage, the type choice of each firm is publicly observed. Thus, each firm, before picking its quality level, knows which type the other firm is. There are three type configurations: (1) one firm is private, the other is open source, (2) each firm is open source, and (3) each firm is private. Each of these three configurations give us a separate subgame and we will first find the Nash equilibrium quality levels for each of these three subgames.

Let's first consider the subgame in (1), where one of the firms has already chosen to be private and the other to be an open source firm, and now they simultaneously pick their quality levels. Let $q_{p r}$ and $q_{o p}$ be the quality choices of the private and open source firms respectively.

Then, the profit of the private firm is given by

$$
\pi_{p r}=P s_{p r}\left(q_{p r}+q_{o p}\right)-c_{p r}\left(q_{p r}\right)=P \frac{q_{p r}+\beta q_{o p}}{q_{p r}+q_{o p}}-q_{p r}^{2} / 2
$$

and the profit of the open source firm is given by

$$
\pi_{o p}=P s_{o p}\left(q_{o p}+q_{p r}\right)-c_{o p}\left(q_{o p}\right)=P \frac{(1-\beta) q_{o p}}{q_{p r}+q_{o p}}-\alpha q_{o p}^{2} / 2
$$

In this subgame, to find the Nash equilibrium, we need to find the best responses of each firm as a function of the quality choice of the other firm. The private firm's best response is given by the condition emerging from the first order condition when it maximizes its profit function, given the quality choice of the open source firm. This condition is given by

$$
\frac{\partial \pi_{p r}}{\partial q_{p r}}=P \frac{q_{p r}+q_{o p}-q_{p r}-\beta q_{o p}}{\left(q_{p r}+q_{o p}\right)^{2}}-q_{p r}=P \frac{(1-\beta) q_{o p}}{\left(q_{p r}+q_{o p}\right)^{2}}-q_{p r}=0
$$

which implies

$$
P(1-\beta) q_{o p}=q_{p r}\left(q_{p r}+q_{o p}\right)^{2}
$$

Likewise, the best response function of the open source firm is given by the following first order condition, 


$$
\frac{\partial \pi_{o p}}{\partial q_{o p}}=P \frac{(1-\beta)\left(q_{p r}+q_{o p}\right)-(1-\beta) q_{o p}}{\left(q_{p r}+q_{o p}\right)^{2}}-\alpha q_{o p}=P \frac{(1-\beta) q_{p r}}{\left(q_{p r}+q_{o p}\right)^{2}}-\alpha q_{o p}=0
$$

which implies

$$
P(1-\beta) q_{p r}=\alpha q_{o p}\left(q_{p r}+q_{o p}\right)^{2}
$$

Equations (1) and (2) summarize the best responses of each firm, thus, solving these equa- tions together will give us the Nash equilibrium strategies in the subgame in the second stage. First of all, dividing the equation (1) by equation (2), we get,

$$
\frac{q_{o p}}{q_{p r}}=\frac{q_{p r}}{\alpha q_{o p}}
$$

which implies $\alpha q_{o p}^{2}=q_{p r}^{2}$, that is $\sqrt{\alpha} q_{o p}=q_{p r}$ in the equilibrium. Plugging this into equation (2), we get

$$
P(1-\beta) \sqrt{\alpha} q_{o p}=\alpha q_{o p}\left(\sqrt{\alpha} q_{o p}+q_{o p}\right)^{2}
$$

Assuming $q_{o p}>0$ and simplifying this, we get

$$
P(1-\beta)=q_{o p}^{2} \sqrt{\alpha}(1+\sqrt{\alpha})^{2}
$$

That is,

$$
q_{o p}^{2}=\frac{P(1-\beta)}{\sqrt{\alpha}(1+\sqrt{\alpha})^{2}}
$$

And, using $\alpha q_{o p}^{2}=q_{p r}^{2}$, we have

$$
q_{p r}^{2}=\alpha \frac{P(1-\beta)}{\sqrt{\alpha}(1+\sqrt{\alpha})^{2}}
$$

Thus, $\left(q_{p r}^{*}, q_{o p}^{*}\right)$ constitutes a Nash equilibrium in this subgame if

$$
q_{o p}^{*}=\sqrt{\frac{P(1-\beta)}{\sqrt{\alpha}(1+\sqrt{\alpha})^{2}}} \quad \text { and } \quad q_{p r}^{*}=\sqrt{\frac{\sqrt{\alpha} P(1-\beta)}{(1+\sqrt{\alpha})^{2}}} .
$$

The market shares at this Nash equilibrium quality choices will then be

$$
s_{o p}=1-\frac{\sqrt{\alpha}+\beta}{1+\sqrt{\alpha}}=\frac{1-\beta}{1+\sqrt{\alpha}}
$$

and 


$$
s_{p r}=\frac{\sqrt{\alpha}+\beta}{1+\sqrt{\alpha}}
$$

The profit level of the open source firm is

$$
\pi_{o p}=P s_{o p}-\frac{\alpha q_{o p}^{2}}{2}=P \frac{(1-\beta)}{1+\sqrt{\alpha}}-\frac{1}{2} \frac{P(1-\beta)}{\sqrt{\alpha}(1+\sqrt{\alpha})^{2}}=P\left(\frac{1-\beta}{1+\sqrt{\alpha}}-\frac{1}{2} \frac{1-\beta}{\sqrt{\alpha}(1+\sqrt{\alpha})^{2}}\right)
$$

And, the profit level of the private firm is

$$
\pi_{p r}=P s_{p r}-\frac{q_{p r}^{2}}{2}=P \frac{(\sqrt{\alpha}+\beta)}{1+\sqrt{\alpha}}-\frac{1}{2} \frac{\sqrt{\alpha} P(1-\beta)}{(1+\sqrt{\alpha})^{2}}=P\left(\frac{\sqrt{\alpha}+\beta}{1+\sqrt{\alpha}}-\frac{1}{2} \frac{\sqrt{\alpha}(1-\beta)}{(1+\sqrt{\alpha})^{2}}\right)
$$

For instance, if $\alpha=1 / 4, \beta=1 / 2$ and $P=4$, then we get $\left(q_{p r}^{*}, q_{o p}^{*}\right)=\left(\frac{2}{3}, \frac{4}{3}\right)$, and the shares are $s_{p r}=2 / 3$ and $s_{o p}=1 / 3$.

Now, let's consider the subgame in (2), where each firm is open source. Then, the profit level of one of the two open source firms, call it firm 1, will be

$$
\pi_{1}=P s_{1}\left(q_{1}, q_{2}\right)-c_{o p}\left(q_{1}\right)=P \frac{q_{1}}{q_{1}+q_{2}}-\alpha q_{1}^{2} / 2
$$

and for the other firm, it will be

$$
\pi_{2}=P s_{2}\left(q_{1}, q_{2}\right)-c_{o p}\left(q_{2}\right)=P \frac{q_{2}}{q_{1}+q_{2}}-\alpha q_{2}^{2} / 2
$$

The best responses for firm 1 and firm 2 are given by the following equations, respectively.

$$
\begin{aligned}
& P \frac{q_{1}+q_{2}-q_{1}}{\left(q_{1}+q_{2}\right)^{2}}-\alpha q_{1}=P \frac{q_{2}}{\left(q_{1}+q_{2}\right)^{2}}-\alpha q_{1}=0 \\
& P \frac{q_{1}+q_{2}-q_{2}}{\left(q_{1}+q_{2}\right)^{2}}-\alpha q_{2}=P \frac{q_{1}}{\left(q_{1}+q_{2}\right)^{2}}-\alpha q_{2}=0
\end{aligned}
$$

which are

$$
\begin{aligned}
& P q_{2}=\alpha q_{1}\left(q_{1}+q_{2}\right)^{2} \\
& P q_{1}=\alpha q_{2}\left(q_{1}+q_{2}\right)^{2}
\end{aligned}
$$

These two conditions imply $q_{1}=q_{2}$, thus the equilibrium is symmetric. Plugging $q_{1}=q_{2}=q^{*}$ into one of the above equations we get, $P q^{*}=\alpha q^{*}\left(2 q^{*}\right)^{2}$, that is, $P=4 \alpha\left(q^{*}\right)^{2}$. Thus, in the equilibrium of this subgame, we get $q_{1}=q_{2}=q^{*}=\frac{1}{2} \sqrt{P / \alpha}$. Since each firm is 
of same type and the quality choices are also the same, their market shares will be the same as well: $s_{1}=s_{2}=1 / 2$. And, the profit level for each firm will be

$$
\pi_{1}=P \frac{q^{*}}{q^{*}+q^{*}}-\frac{\alpha q^{* 2}}{2}=\frac{P}{2}-\alpha \frac{\left(\frac{1}{2} \sqrt{\frac{P}{\alpha}}\right)^{2}}{2}=\frac{P}{2}-\alpha \frac{1}{8} \frac{P}{\alpha}=\frac{3 P}{8}
$$

Again, as an example, consider the same parameter values above, that is, $\alpha=1 / 4, \beta=$ $1 / 2$ and $P=4$. For these values, the quality choices are $q_{1}=q_{2}=q^{*}=\frac{1}{2} \sqrt{4 /\left(\frac{1}{4}\right)}=2$, and each firm ends up with a profit level $\pi_{i}=3 / 2$.

The reason that the equilibrium level of profit is not affected by neither $\alpha$ nor $\beta$ is that both firms are open source, thus, both of them have the cost advantage by the same fraction so the effect of $\alpha$ cancels out, also both firms are unfavored in the market due to consumer bias by the same amount, so that effect is also neutralized. However, the quality levels are affected by $\alpha$, since it affects the cost of it.

Finally let's consider the subgame in (3), where each firm has chosen to be private. Similar to the subgame in (2), the quality choices will be symmetric and the they will equally share the market. To see this, let's write down the profit of each firm.

$$
\pi_{i}=P s_{i}\left(q_{i}, q_{j}\right)-c_{p r}\left(q_{i}\right)=P \frac{q_{i}}{q_{i}+q_{j}}-q_{i}^{2} / 2
$$

for $i=1,2$ and $j$ is the other firm. The best response of firm $i$ is given by

$$
P \frac{q_{i}+q_{j}-q_{i}}{\left(q_{1}+q_{2}\right)^{2}}-q_{i}=P \frac{q_{i}}{q_{i}+q_{j}}-q_{i}=0
$$

By symmetry, we get $q_{1}=q_{2}=q^{* *}=\frac{1}{2} \sqrt{P}$. The shares will be equal: $s_{1}=s_{2}=\frac{1}{2}$. The profit of firm $i$ will then be

$$
\pi_{i}=P \frac{q^{* *}}{q^{* *}+q^{* *}}-\frac{\left(q^{* *}\right)^{2}}{2}=\frac{P}{2}-\frac{P}{4}=\frac{P}{4}
$$

For the same parameter values above, we have $q^{* *}=1$ and $\pi_{i}=1$. Again, since both firms are of the same type in this case, the profit levels are unaffected by $\alpha$ or $\beta$, since there is no spillover for none of the firms and the biases on the consumer side offset each other.

Now, we can look at the best responses in the first stage. What is the best choice if the other firm picks to be an open source? And, likewise, what is the best choice if the other firm picks to be a private firm? 


\subsection{Best Response to a Private Firm}

Let's assume that the other firm picks to be a private firm. Then, choosing to be a private firm brings a profit of $P / 4$. However, choosing to be an open source firm brings a profit of

$$
P\left(\frac{1-\beta}{1+\sqrt{\alpha}}-\frac{1}{2} \frac{1-\beta}{\sqrt{\alpha}(1+\sqrt{\alpha})^{2}}\right)
$$

as shown above. Thus, if

$$
\frac{1}{4}>\frac{1-\beta}{1+\sqrt{\alpha}}-\frac{1}{2} \frac{1-\beta}{\sqrt{\alpha}(1+\sqrt{\alpha})^{2}}
$$

then it is best response to choose to be a private firm. Otherwise, being an open source firm is the best response. To ease notation, define $a=\sqrt{\alpha}$. Since $\alpha \in(0,1)$ and $f(x)=\sqrt{x}$ is an increasing transformation, we also have $a \in(0,1)$. Now, plugging $a$ for $\sqrt{\alpha}$, and arranging it we get,

$$
\frac{a\left(a^{2}+2 a+1\right)}{2 a^{2}+2 a+1}-2(1-\beta)>0
$$

Note that, given the other firm is private, if the inequality holds, then it is best response to be a private firm, otherwise best response is to pick to be an open source firm. Plotting this inequality for different values of $a$ and $\beta$, we get the following pattern.

(i) For any $\beta>0.333$, the inequality holds for any $a$.

(ii) For any $\beta<0.333$, there exists an $\bar{a}$ level as a function of $\beta$, such that, for $a<\bar{a}$, it holds, and for $a>\bar{a}$ it does not hold. In other words,

Lemma 1. Given that the other firm is a private firm. Then,

(i) For any $\beta>0.333$, the best response is to be private, for any a.

(ii) For any $\beta<0.333$, there exists an $\bar{a}$ such that, for $a<\bar{a}$ the best response is to be private, for $a>\bar{a}$ the best response is to be open source.

\subsection{Best Response to an Open Source Firm}


Now, if the other firm is an open source firm, then what is the best response? Picking to be an open source firm brings a profit equal to $3 P / 8$. However, choosing to be a private firm brings a profit equal to

$$
P\left(\frac{\sqrt{\alpha}+\beta}{1+\sqrt{\alpha}}-\frac{1}{2} \frac{\sqrt{\alpha}(1-\beta)}{(1+\sqrt{\alpha})^{2}}\right)
$$

as shown above. Thus, best response to an open source firm is to pick to be an open source firm if

$$
\frac{3}{8}>\frac{\sqrt{\alpha}+\beta}{1+\sqrt{\alpha}}-\frac{1}{2} \frac{\sqrt{\alpha}(1-\beta)}{(1+\sqrt{\alpha})^{2}}
$$

Otherwise, best response is being a private firm. Plugging $a$ for $\sqrt{\alpha}$, and arranging it we get,

$$
0>5 a^{2}-2 a+4 a \beta+8 \beta-3
$$

Note that, given the other firm is open source, if the inequality holds, then it is best response to be an open source firm, otherwise best response is to pick to be a private firm. Plotting this inequality for different values of a and $\beta$, we get the following pattern.

(i) For any $\beta>0.3765$, the inequality does not hold for any $a$.

(ii) For any $\beta<0.3765$, there exists an $\overline{\bar{a}}$ level as a function of $\beta$, such that, for $a<\overline{\bar{a}}$ it holds, for $a>\overline{\bar{a}}$ it does not hold. That is,

Lemma 2. Given that the other firm is an open source firm. Then,

(i) For any $\beta>0.3765$, the best response is to be private, for any a.

(ii) For any $\beta<0.3765$, there exists an $\overline{\bar{a}}$ such that, for $a<\overline{\bar{a}}$ the best response is to be open source, for $a>\overline{\bar{a}}$ the best response is to be private.

\subsection{Subgame Perfect Nash Equilibrium}

Finally to find the set of subgame perfect Nash equilibrium, we need to find the Nash equilibrium in the reduced game, that is, we need to combine the two best responses depicted above in Lemma 1 and Lemma 2. Then, we will be able to understand which type configuration will emerge in the equilibrium, for any given pair of $\alpha$ and $\beta$ values.

Case 1: $\beta>0.3765$. In this case, best response is always to be private. Thus, when $\beta>$ 0.3765 , there is only one equilibrium, in which each firm prefers to be private. This is because 
the consumer bias towards the private firm is high enough. Thus, within this case there is only one subgame perfect Nash equilibrium outcome: Each firm picks to be private in the first stage and then in the second stage each pick a quality level $q_{1}=q_{2}=q^{* *}=\frac{1}{2} \sqrt{P}$ and share the market equally. Thus, a private and an open source firm cannot coexist.

Case 2: $0.3765>\beta>0.333$. In this case, it is still best response to be private if the other firm is private. However, if the other firm is an open source firm, then the best response is determined by the value of $a$. If $a>\overline{\bar{a}}$, then being private is also best response to an open source firm. Thus, both firms will again be private. If, however, $a<\overline{\bar{a}}$, then the best response is to be open source, if the other firm is open source. Thus, in this latter case, we have another equilibrium, where both firms are open source. Therefore, in this range of $\beta$ values, there always exists a subgame perfect Nash equilibrium outcome where each firm picks to be private, for any a values, and pick $q_{1}=q_{2}=q^{* *}=\frac{1}{2} \sqrt{P}$ in the second stage, and share the market equally. And if $a<\overline{\bar{a}}$, then there is also this other subgame prefect Nash equilibrium outcome where each firm is open source, and each pick $q_{1}=q_{2}=q^{*}=$ $\frac{1}{2} \sqrt{P / \alpha}$ in the second stage, and share the market equally. $\diamond$

Case 3: $0.333>\beta$. This case is tricky. By the part (ii) of Lemma 1, we know that if the other firm is private, then the best response is to be private if $a<\bar{a}$, and to be open if $a>\bar{a}$. Also, by the part (ii) of Lemma 2, we know that if the other firm is open source, then the best response is to be open source if $a<\overline{\bar{a}}$, and to be private if $a>\overline{\bar{a}}$. That is, if the other firm is private, then best response is

$$
B R_{i}(j=\text { private })=\left\{\begin{array}{l}
\text { private if } a<\bar{a} \\
\text { open if } a>\bar{a}
\end{array}\right.
$$

If the other firm is open source, then best response is

$$
B R_{i}(j=\text { open })= \begin{cases}\text { open } & \text { if } a<\overline{\bar{a}} \\ \text { private } & \text { if } a>\overline{\bar{a}}\end{cases}
$$

Now, we need to check the relative positions of these two functions, $\bar{a}(\beta)$ and $\overline{\bar{a}}(\beta)$. These two threshold functions, $\bar{a}(\beta)$ and $\overline{\bar{a}}(\beta)$ intersect at an interim value of $\beta \cong 0.215$. When $\beta=0, \bar{a}(0) \cong 0.53$ and $\overline{\bar{a}}(0)=1$. When $\beta=0.33$, then $\bar{a}(0.33)=1$ and $\overline{\bar{a}}(0.33) \cong$ 
0.35. Also, $\bar{a}(\beta)$ is a monotonically increasing function and $\overline{\bar{a}}(\beta)$ is a monotonically deccreasing function. Thus, we have the graph below in Figure 1, for $\beta$ values less than 0.333 .

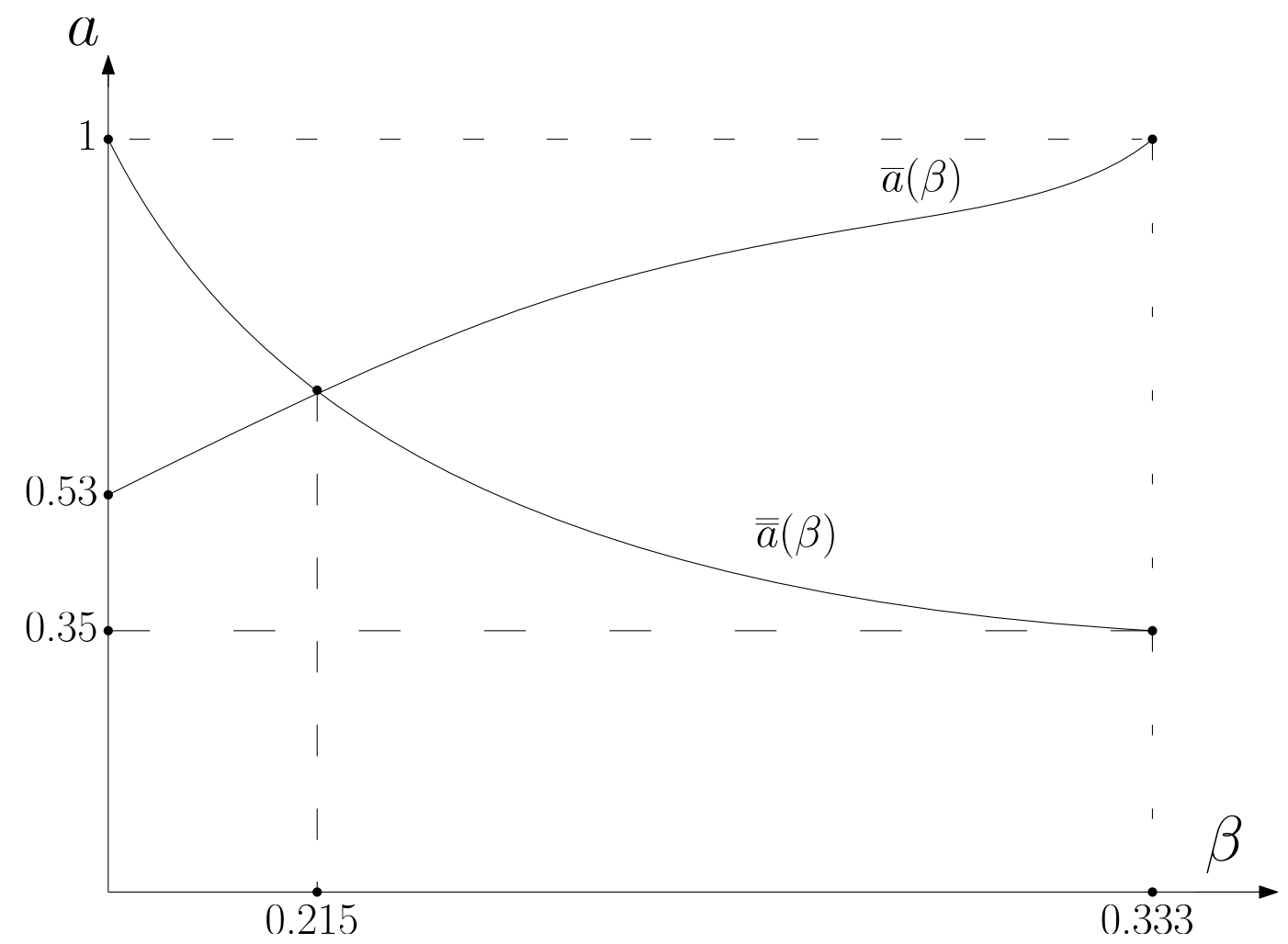

Figure 1. The threshold functions.

If $a>\max \{\bar{a}, \overline{\bar{a}}\}$, then the best responses are $B R_{i}(j=$ private $)=$ open and $B R_{i}(j=$ open $)=$ private. Thus, the only subgame perfect Nash equilibrium outcome is where one of the firms is a private firm, and the other is an open source firm, where the quality choices are

$$
q_{o p}^{*}=\sqrt{\frac{P(1-\beta)}{\sqrt{\alpha}(1+\sqrt{\alpha})^{2}}} \quad \text { and } \quad q_{p r}^{*}=\sqrt{\frac{\sqrt{\alpha} P(1-\beta)}{(1+\sqrt{\alpha})^{2}}}
$$

and the market shares are $s_{o p}=\frac{1-\beta}{1+\sqrt{\alpha}}$ and $s_{p r}=\frac{\sqrt{\alpha}+\beta}{1+\sqrt{\alpha}}$. Thus, a private and an open source firm coexist in the equilibrium, for these parameter values.

If $a<\max \{\bar{a}, \overline{\bar{a}}\}$, then the best responses are $B R_{i}(j=$ private $)=$ private and $B R_{i}(j=$ open $)=$ open. Thus, there are 2 subgame perfect Nash equilibrium outcomes, one with two private firms and the other with two open source firms, equivalent to those two outcomes in Case 2. Thus, a private and an open source firm cannot coexist. 
If $\bar{a}>a>\overline{\bar{a}}$, then, to be private is a best response to both choices of the other firm. Thus, the only subgame perfect Nash equilibrium outcome is the one where both firms are private as in Case 1. $\diamond$

Let's interpret these three cases now. In Case 1, the only possible configuration is that both firms are private. This is because there is a large enough bias towards the private firm's product, and it never pays off to be an open source firm. In Case 2, however, we have relatively lower $\beta$ values, but still high enough so that both firms being private is still an equilibrium. However, there is a new equilibrium outcome as long as a is low enough, where each firm picks to be open source. The reason is that since a is low enough, now the cost of quality is low enough and it is reasonable to be an open source firm, if the other is also an open source firm as well. Yet, if the other firm is private, the negative consumer bias effect still overcomes the effect coming from the low cost of quality. In Case 3, the interesting part is where we have both type of firms in the equilibrium: one firm is private and the other is open source. This is the outcome when $\beta$ is low enough, $\beta<0.333$, so that the negative consumer bias against the open source product is not as strong, which makes it reasonable to be an open source firm, if the other firm is private. And, the cost of quality for the open source firm is high enough, through $a$ high a where $a>\max \{\bar{a}, \overline{\bar{a}}\}$, which makes it reasonable to be a private firm, if the other firm is open source. Thus, within this set of parameters, the two types of firms coexist, and note that this is the unique outcome in this set of parameters. We summarize our findings in Proposition1 below. Recall, $a=\sqrt{\alpha}$. And also, to ease notation further, define $a_{\max }=\max \{\bar{a}, \overline{\bar{a}}\}$.

Proposition 1. If $\beta<1 / 3$ and $a>a_{\text {max }}$, then in the unique equilibrium outcome, one of the firms is private and the other firm is an open source firm. For any other parameter combination, the equilibrium is symmetric and coexistence does not occur.

Thus, for each type of firms to coexist, we must have small enough consumer bias (small $\beta$ ) and small enough spillovers (large $\alpha$ ). For instance, if $\beta=0.25$, then $\bar{a}=0.676$ and $\overline{\bar{a}}=$ 0.558 , that is, $a_{\max }=0.676$. Then, $\sqrt{\alpha}=a>0.676$ implies $\alpha>0.457$. Thus, if $\beta=0.25$ and $\alpha>0.457$, then in the equilibrium, one firm is private and the other is open source.

\section{CONCLUSION}

We studied a simple model of investment in $R \& D$ with spillover effect present in the open source community and consumer bias towards the private firm. We explored the 
conditions under which two types of firms, a private firm and an open source firm can coexist in the market. We developed and used a simple and tractable game theoretical model, in which spillovers on the open source production are captured by a single parameter, $\alpha \in[0,1)$, and positive consumer bias for the privately produced good is also summarized by another single parameter, $\beta \in(0,1]$. We solved for the equilibrium strategies, and showed that for large enough consumer bias, the two types cannot coexist, however when the consumer bias is relatively low and the spillover effect is not too strong, then in the equilibrium coexistence occurs. 


\section{REFERENCES}

Admati, A. R. and Perry, M. (1991), "Joint Projects without Commitment”, The Review of Economic Studies, 58, 259-276.

Aghion, P., Harris, C., Howitt, P. and Vickers, J. (2001), "Competition, Imitation and Growth with Step-by-Step Innovation", Review of Economic Studies, 68, 467-492.

Akbulut, S and Yllmaz, M. (2015), “A Dynamic Model of Mixed Duopolistic Competition: Open Source vs. Proprietary Innovation”, Theoretical Economics Letters, 5, 730-738.

Aoki, R. (1991), "R\&D Competition for Product Innovation: An Endless Race”, The American Economic Review, 81, 252-256.

Atal, V. and Shankar, K. (2014), “Open Source Software: Competition with A Public Good”, Atlantic Economic Journal, 42(3), 333-345.

Athey, S. and Ellison, G. (2014), "Dynamics of Open Source Movements", Journal of Economics \& Management Strategy, 23(2), 294-316.

Bitzer, J. (2004), "Commercial versus open source software: the role of product hetero- geneity in competition", Economic Systems, 28, 369-381.

Bitzer, J., Schrettl, W. and Schröder, P. J. H. (2007), "Intrinsic motivation in open source software development", Journal of Comparative Economics, 35, 160-169.

Casadesus-Masanell, R. and Ghemawat, P. (2006), "Dynamic Mixed Duopoly: A Model Motivated by Linux vs. Windows", Management Science, 52(7), 1072-1084.

Casadesus-Masanell, R. and Llanes, G. (2011), “Mixed Source”, Management Science, 57(7), 1212-1230.

Caulkins, J. P., Feichtinger, G., Grass, D., Hartl, R. F., Kort, P. M., and Seidl, A. (2013), "When to make proprietary software open source", Journal of Economic Dynamics and Control, 37, 1182-1194.

Economides, N. and Katsamakas, E. (2006), "Two-Sided Competition of Proprietary vs. Open Source Technology Platforms and the Implications for the Software Industry", Management Science, 52(7), 1057-1071.

Erkal, N. and Minehart, D. (2014), “Optimal Technology Sharing Strategies in Dynamic Games of R\&D”, Journal of Economics \& Management Strategy, 23(1), 149-177.

Fershtman, C. and Markovich, S. (2010), "Patents, imitation and licensing in an asymmet- ric dynamic R\&D race", International Journal of Industrial Organization, 28(2), 113-126.

Grossman, G. M. and Shapiro, C. (1987), “Dynamic R\&D Competition”, The Economic Journal, 97, 372-387.

Haruvy, E., Sethi, S. P. and Zhou, J. (2008),“Open Source Development with a Commer- cial Complementary Product or Service", Production and Operations Management, 17(1), 29-43

Hasnas, I., Lambertini, L. and Palestini, A. (2014), “Open Innovation in a dynamic Cournot duopoly”, Economic Modelling, 36, 79-87.

Jaisingh, J, See-To, E. W. K. and Tam K. Y. (2014), "The Impact of Open Source Software on the Strategic Choices of Firms Developing Proprietary Software”, Journal of Management Information Systems, 25(3), 241-276.

Johnson, J. P. (2002), “Open Source Software: Private Provision of a Public Good”, Journal of Economics \& Management Strategy, 11(4), 637-662.

Kort, P. M. and Zaccour, G. (2011), "When Should a Firm Open its Source Code: A Strategic Analysis", Production and Operations Management, 20(6), 877-888.

Lerner, J., Pathak, P. A. and Tirole, J. (2006), "The Dynamics of Open-Source Contrib- utors", The American Economic Review, 96(2), 114-118.

Lerner, J. and Tirole, J. (2005), “The Economics of Technology Sharing: Open Source and Beyond”, The Journal of Economic Perspectives, 19(2), 99-120. 
Lerner, J. and Tirole, J. (2002), "Some Simple Economics of Open Source”, Journal of Industrial Economics, 50(2), 197-234.

Li, C. and Ji, C. (2010), “Innovation, licensing, and price vs. quantity competition”, Economic Modelling, 27, 746754.

Llanes, G. and de Elejalde, R. (2013), "Industry equilibrium with open-source and pro- prietary firms", International Journal of Industrial Organization, 31, 36-49.

Marx, L. E. and Matthews, S. A. (2000), "Dynamic Voluntary Contribution to a Public Project", The Review of Economic Studies, 67, 327-358.

Modica, S. (2012), “Open Source without Free-Riding”, Economia politica, 2, 247-260.

Mustonen, M. (2005), “When Does a Firm Support Substitute Open Source Program- ming?”, Journal of Economics \& Management Strategy, 14(1), 121-139.

Reisinger, M., Ressner, L., Schmidtke, R. and Thomes, T. P. (2014), "Crowding-in of com- plementary contributions to public goods: Firm investment into open source software", Journal of Economic Behavior \& Organization, 106, 78-94.

Suh, J. and Yilmaz, M. (2017), "Economics of Open Source Technology: A Dynamic Approach", working paper.

Ylldırım, H. (2006), "Getting the ball rolling: Voluntary contributions to a large-scale public project", Journal of Public Economic Theory, 8(4), 503-528. 